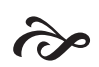

\title{
KLANLEDERENS GRAVSTED BETYDNINGEN AV TERRITORIALITET BLANT PALESTINERE I ISRAEL
}

\author{
Dannelsen av Israel førte til at palestinsk klanterritorialitet fikk \\ fornyet politisk betydning.
}

DAG TUASTAD

Ti kilometer sør for Libanon, i det sentrale Galilea nord i Israel, ligger Deir al-Asad. Den muslimske byen er bygd rundt det som en gang var et gammelt kloster, men som nå er den eldste moskeen i byen. Opprinnelsesmyten til den største klanen i byen, Asadi, som utgjør om lag 7000 av byens 13000 innbyggere, gir en forklaring på hvorfor byen er muslimsk, men samtidig har deir, kloster, som del av navnet sitt. Denne artikkelen er historien om denne historien. Den er samtidig historien om hvordan klanterritorialitet, en klans bånd til jorda, er formet over generasjoner og utgjør en kjerne i israelske palestineres antikoloniale, kollektive bevissthet. ${ }^{1}$

\section{DE SOM IKKE FLYKTET}

Mens det har vært mange studier av hvorfor palestinerne flyktet i $1948^{2}$ har det vært få av hvorfor de som ikke flyktet ble igjen. Hvorfor flyktet eksempelvis ikke landsbybeboerne i Deir al-Asad da landsbyen ble erobret av jødiske styrker den 30. oktober 1948? Samtlige av landsbybeboerne ble da samlet på et åpent jorde. Så ble tolv personer plukket ut, stilt opp, og skutt og drept foran skrekkslagne familiemedlemmer og sambygdinger. Til tross for denne brutale oppfordringen om å forlate området ble landsbybeboerne igjen. Det var en akutt overhengende fare for å bli utsatt for massedrap slik palestinske innbyggere under Galilea-kampanjen høsten 1948 kom til å bli utsatt for, som i Eilabun, Safsaf, Saliha og Sa'sa. ${ }^{3}$

Jeg vil argumentere at dette har å gjøre med territorialitet, en gruppes tilhørighet og beskyttelse av sted. ${ }^{4}$ Territorialitet utgjør kjernen i det vi kan kalle den rurale palestinske befolkningens praktiske bevissthet; den innforståtte, uartikulerte kunnskapen som motiverer aktørers handlingsvalg. ${ }^{5}$ Et sentralt element i denne bevisstheten er hvordan fysisk rom blir til sosialt rom, og hvordan dette igjen konstituerer sosial identitet. På den palestinske landsbygda hvor jordbrukere var organisert gjennom endogame klaner var forbindelsen til jorda spesielt sterk. Denne tilhørigheten ble ytterligere forsterket gjennom koblingen til religiøs identitet, overbevisningen om at jorda var hellig, islamsk jord, gitt muslimene for evig tid.

Denne artikkelen er et dypdykk i hvordan denne sammensmeltingen er historisk og sosialt 
konstruert, med utgangspunkt i en klans opprinnelsesmyte. Den daværende landsbybefolkningens sterke territorialitet gjorde at de ikke flyktet, til tross for det de måtte ha oppfattet som en overhengende fare for å bli drept og at kvinner kunne bli utsatt for overgrep.

Lokalbefolkningens praktiske bevissthet, deres underliggende kulturelle forestillinger om jorda og stedets opprinnelse, representerer en spesiell, ofte oversett politisk kraft: den er grunnleggende anti-hegemonisk og bidrar vedvarende til å delegitimere den jødiske statens koloniseringsprosjekt.

\section{ASADIS OPPRINNELSESMYTE}

Av de seks distriktene Israel er administrativt delt inn i, skiller ett distrikt seg ut, norddistriktet. I ingen andre distrikt er andelen israelske arabere eller israelske palestinere, som de gjerne omtaler seg selv som - større. Over halvparten av innbyggerne (54 prosent), 750 ooo mennesker, er israelske palestinere mens antall jøder er på rundt 600 ooo. Om lag 540 ooo av de israelske palestinerne er muslimer. De er etterkommere av de 100 ooo av en palestinsk befolkning på nærmere 800 ooo som var igjen innenfor det som ble Israels grenser da våpenhvilen mellom Israel og nabolandene ble inngått i 1949. ${ }^{6}$ Blant landsbyene som da ble erobret i Galilea uten at befolkningen flyktet var Deir al-Asad, og de omkringliggende landsbyene Nahf, Rama, Majd al-Kurum og Bani. Jeg kom første gang til Deir al-Asad i 1989 for å bo der et år i forbindelse med feltarbeid i sosialantropologi. Jeg har siden besøkt området regelmessig, senest tre måneder høsten $2015 .^{7}$

Den gang, som i dag, hadde innbyggerne en sterk klanidentitet. Men klanidentiteten var ikke en eksklusiv politisk identitet. Mange, for ikke å si de fleste, hadde både sterk klantilhørighet og var samtidig glødende palestinske nasjonalister. I bunn av deres palestinske identitet var forholdet til jorda. Israel hadde konfiskert store landområder fra Deir al-Asad og de omkringliggende landsbyene. Jorda ble overtatt av nyinnflyttede jødiske immigranter som var uvitende om lokal mening knyttet til stedet - hvis mening for palestinerne utgjorde essensen av deres sosiale og etniske identitet. Myten om Deir al-Asads opprinnelse, og hvordan stedet fikk sitt navn, er eksempelvis noe alle barn i byen får inn med morsmelken. Nedenfor er denne opprinnelsesmyten til Asadi-klanen presentert, fortalt av Maqmon al-Asad, en lærer og lokal ekspert på Asadis familiehistorie.

Muhammad al-Jilani, som Muhamad al-Asad først het, var en etterkommer etter Abd al-Qadir Jilani, en berømt sufi-sheik som levde i Bagdad på 110o-tallet, fortalte Mahmod. Også Muhammad var sufi-leder respektert i vide kretser, og en dag ble han kalt inn til et møte med selveste Selim I, den osmanske sultanen, da han var i området. Selim fortalte Muhammad om et særlig urolig område i Galilea i Akka-distriktet, rundt klosteret Deir al-Khadr (Elias' kloster), ved den kristne landsbyen Bani. Klosteret lå langs dalsiden opp fra karavaneveien mellom Damaskus og Akka, og var derfor vanskelig å innta. Det var grunnen til at det hadde blitt et fristed for røvere og opprørere. Sultanen ba Muhammad dra og slå seg ned der. Muhammad dro av gårde på sitt esel for å utføre oppdraget han var gitt. Han stanset ved en bekk hvor han vasket seg og ba. Mens han ba kom en løve og åt eselet hans. Muhammad konsentrerte seg bare om bønnen og la ikke merke til løven. Da han var ferdig med å be, var løven, som hadde spist eselet, mett og derfor ikke aggressiv lenger, men som et hvilket som helst annet husdyr. Muhammad ble ikke redd da han så at eselet var blitt til en løve, han stolte på Gud. Han satte seg på løven og red avgårde. Da han var fremme ved klosteret, ble de som var der grepet av redsel og 
flyktet i panikk. Muhammad slo seg ned der og fikk navnet al-Asad (løven). Stedet ble oppkalt etter ham og fikk navnet Deir al-Asad (løvens kloster). Muhammad al-Asad fikk fire guttebarn som Asadi-klanens forgreininger stammer fra; sheik Muhammad Hafed, sheik Muhammad Nami, sheik Muhammad Sufi og sheik Muhammad Mahfod.

Da jeg først hørte denne fortellingen gjorde eventyrdelen, al-Asad ridende på en løve, at jeg så på den gjenværende delen av historien, om forfaren som en som hadde møtt sultanen, som like urealistisk. Det at det ved al-Asads gravsted stadig ble foretatt ulike religiøse ritualer (som jeg kommer tilbake til senere i artikkelen) gjorde at jeg assosierte myten med religiøs synkretisme, mellom islam og forfedredyrkelse.

Men det fantes også en versjon av Asadiklanens opprinnelseshistorie som ikke inkluderte den mytologiske delen, men derimot skriftlig, historisk dokumentasjon. Da planene om å konfiskere land fra Deir al-Asad og nabolandsbyene ble kjent for landsbybeboerne på slutten av 1950årene gikk noen medlemmer av Asadi-klanen til sak mot den israelske staten. De hevdet at de hadde i sin besittelse historiske dokumenter som viste at jorda som skulle konfiskeres var forært dem av den osmanske sultanen, slik det het i deres opprinnelsesmyte. Dokumentene viste, hevdet landsbybeboerne, at området israelske landmyndigheter planla å konfiskere var opprettet som waqf-land, tilhørende al-Asad moskeen, og gitt hans etterkommere å forvalte. Israel brukte osmansk lov for å konfiskere land. Staten definerte jorda de ønsket å ta som «miri-land», land som tilfalt «amiren». ${ }^{8}$ Men så lenge samme land var gitt landsbybeboerne av den osmanske sultanen som waqf-land trumfet dette miri-land ifølge saksøkerne. I retten la de fram waqfiyaen, avtalen eller charteret om forvalting av eiendommen, inn- gått av sultan Selim i 1516 med Asadi-klanens forfar, Muhammad al-Asad. De la fram en kopi av den opprinnelige avtalen mellom sultanen og alAsad hvor området som var inkludert som waqfland var detaljert beskrevet. I avtalen het det, i den israelske professoren Aharon Layish oversettelse: ${ }^{9}$

The following demarcate the monastery on all sides: in the south-the zawiya of al-Was'a, which separates the two from the above-mentioned al-Bina village that has been dedicated as a waqf; in the east - the watercourse which runs down from al-Jalsa to the area east of the al-Fuqaniyya spring and to the Red Vineyard through which the road passes that separates the lands of the monastery from the lands of al-Bina; in the north - the mountain on which gusts of wind blow into the caves; and in the westthe area facing the mountain known as alHamida, [which borders on the aforementioned Khirbat Hawtal; in the east, there is also the watercourse [that runs] from al-Khashab; in the west, there is also the road which separates the lands of the monastery from the lands of al Bina; in the north, there is also the road on which traffic is heavy which separates the lands of Khirbat Hawtal from the lands of al-Bina and Nahf].

Avtalen definerte hele området planlagt konfiskert som waqf-land. Dokumentet som ble lagt fram i retten var en nedskrevet kopi av den opprinnelige avtalen. Det var brukt i en rettsak i sharia-domstolen i Akka i 1838 der noen av forvalterne av waqfiyaen var involvert. Sentralt i spørsmålene retten måtte svare på nå var: Var dette en ekte kopi og var det opprinnelige dokumentet ekte?

Takket være den israelske professoren i islamsk lov og historie nevnt ovenfor, Aharon Layish ved Hebrew University i Jerusalem, er disse spørsmålene blitt svært godt belyst. Layish hadde islamiseringen av Palestina under den første osmanske perioden på 1400-1600-tallet, inklu- 
dert av kristne landområder og religiøse bygninger som et spesialfelt. Han fattet følgelig interesse for rettsaken landsbybeboerne hadde anført mot staten. Layish fikk tilgang til alle rettsdokumentene i saken, og jo mer han studerte disse, jo mer forbauset ble han. Layish finner det hevet over tvil at de fremlagte dokumentene var ekte. Al-Asad, som i myten kom ridende til området på en løve, var den historiske personen, en velkjent sufi-sheik, som landsbyboerne hevdet han var. Analysen av formuleringer, skrift, språk, referanser, skikkelser og kontekst, pekte alt i samme retning. al-Asad var faktisk gitt waqfiyaen direkte av sultanen. ${ }^{10}$

Hvorfor skulle sultanen inngå en avtale med en lokal sufi-sheik om å opprette en waqf-eiendom i et fjernt kloster i Galilea? Mange av klostrene som ble etablert av korsfarerne på 1100-tallet, som Elias-klosteret ved den gamle kristne landsbyen Bani, var strategisk plassert oppe i dalsida med oversikt over karavaneruta mellom Akka og Damaskus, og fungerte også som militære forlegninger. De kristne og deres jord skulle beskyttes. Men slike forlegninger ble også sentre for uro, hvor både røvere og opprøre søkte tilflukt. Etter den osmanske erobringen av Palestina og Syria fra mamlukene i 1516 ønsket osmanerne følgelig å styrke kontrollen sin i området. Sultan Selim I reiste derfor rundt i den nylig erobrede provinsen for å islamisere strategiske områder kontrollert av kristne eller av opprørere, hvorav Elias-klosteret ved Bani. Å islamisere klosteret var helt i tråd med daværende osmansk kontrollpolitikk, islamisering var en politisk metode for å sikre osmansk herredømme. Flere muslimske landsbyer har følgelig «ريد/deir eller dayir», som betyr kloster, som forstavelse. En av de mest kjente «deir-landsbyene», Deir Yassin, hvor jødiske paramilitære grupper gjennomførte 1948-krigens kanskje mest grusomme massakre, var eksempelvis muslimsk. Islamiseringen innebar å opphøye stedet til et autonomt område, direkte underlagt sultanen heller enn den lokale guvernøren (walien). Deir al-Asad ble et av slike autonome steder, Qarya mustathnaya 'an al 'sultanat, hvor begrunnelsen var at den lokale autonome walien, oftest en sufisheik som i dette tilfellet, hadde unike religiøse kvaliteter.

Layish konkluderer som nevnt med at waqfiyaen til al-Asad og hans etterkommere, avtalen som gir dem rett til å forvalte jorda som alAsads etterkommere til evig tid, er et ekte, uforfalsket historisk dokument. Det mest oppsiktsvekkende med saken, skriver Layish, er at noe som til de grader ser ut til å være en lokal legende viser seg i all hovedsak å være en ekte beskrivelse av virkelige, historiske hendelser. ${ }^{11}$

\section{LANDKONFISKERINGENE}

I sin kjennelse konkluderte også israelsk høyesterett med at dokumentene framlagt av saksøkerne var ekte. De hadde vitterlig blitt tildelt området som waqf-land. Men dette var ikke tilstrekkelig grunn til å ikke konfiskere jorda, og i 1964 ble den jødiske byen Karmiel etablert på jord eid av landsbybeboerne. 2000 av 8000 dunum (dekar) land var igjen for Deir al-Asad, mens 12000 av 48000 dunum var igjen for nabolandsbyene. ${ }^{12}$ Næringsgrunnlaget gjennom jordbruk var med konfiskeringene fjernet. Det er symptomatisk at en familie som hadde fått fratatt sin jord søkte om å få flytte til Karmiel, på jord de selv hadde eid, men fikk avslag. «Karmiel was not built in order to solve the problems of the people in the surrounding area», het det fra den israelske boligministeren. ${ }^{13}$

Israel lyktes på kort sikt med sitt koloniseringsprosjekt av de gjenværende, israelske palestinerne. De konfiskerte mesteparten av deres land uten kostnader i form av voldelig motstand. Men om Israel lyktes i å etablere den jødiske byen Karmiel på de arabiske nabolandsbyenes jord, ligger byen 
i dag som et åpent sår i landskapet, i perspektivet til araberne i småbyene rundt. Kontakten mellom de jødiske og palestinske innbyggerne er minimal og preget av fiendskap. I år 2000 kom det til voldsomme fysiske konfrontasjoner mellom ungdom fra Karmiel og ungdom fra de omkringliggende arabiske småbyene, på veien som forbinder stedene. "Jeg gikk for slåss, for å dø om nødvendig», fortalte en ungdom fra Deir al-Asad meg. Politiet skjøt over hodene på de to gruppene og hindret konfrontasjonen i å utarte seg, mens 13 israelske palestinere ble skutt og drept av israelsk politi andre steder i landet. I en rapport fra et regjeringsoppnevnt utvalg om opptøyene het det: «The process, through which Arab citizens of Israel lost their land remains an unhealed wound, a key factor in the sense of alienation and deprivation experienced by the Arab minority in Israel.» ${ }^{14}$ Rapporten anbefalte en offentlig unnskyldning, kompensasjon og en endring av landpolitikken lignende den Australia har gjennomført med sin urbefolkning. At jordkonfiskeringene forblir et åpent sår gir grunn til å utforske nærmere hva som gjør at såret ikke leges, og hvordan forholdet til jorda og minnet om konfiskeringene holdes i live.

\section{SOSIALT MINNE}

Et kroppsliggjort sosialt minne er svært vanskelig å utviske. Paul Connerton siterer i sin monografi om sosialt minne hvordan ulike typer gester brukt av napolitanere i UsA kan spores helt tilbake til det antikke Hellas og Roma. ${ }^{15}$ Handlingene og måtene å oppføre seg på overføres gjennom generasjoner, ubevisst, gjennom kroppsliggjøring, gestikulering, særegne uttrykk og handlinger fylt med innforstått mening. På lignende måte har mening og identitet knyttet til al-Asads gravsted vært del av sosiale praksiser ved al-Asads gravsted over generasjoner. Dette har sammenheng med hvordan sufi-sheiker som al-Asad helt fra middel- alderen av ble betraktet som velsignet (baraka) og angivelig utstrålte en spesiell, mystisk, gudommelig kraft. ${ }^{16}$

Denne kraften tok de med seg i graven, i den forstand at deres gravsteder ikke bare var hellige, men også kilder for mirakuløse hendelser. Et sufibrorskap var ikke bare en tariq, en religiøs, mystisk retning. Sufi-sektene kunne også være definert av stedet hvor karismatiske sufi-ledere prekte og gikk i ekstase. Slike steder ble kalt zawiaer, hvor sufi-brorskap og gravstedet til dets stifter smeltet sammen, og ble tilholdsstedene for brorskapet også etter stifteres død. Stedene ble læresteder og hospitser, og la som i Deir al-Asad grunnlaget for større bosetninger. Når sufisheiken døde ble han lagt i en kiste i zawiaen de hadde grunnlagt. En zawiya betegnet slik et gravsted, en moske og et religiøst brorskap. ${ }^{17} \mathrm{Og}$ det er her, ved al-Asads zawiya, ulike ritualer har utspilt seg over generasjoner, ritualer som forbinder deltakerne med al-Asads forfar og samtidig med stedet forfaren ligger begravd.

En dag under mitt første feltarbeid i Deir alAsad på våren 1990, observerte jeg noen tenåringer som spilte basketball i gaten utenfor al-Asad-moskeen hvor zawiaen er integrert. Før de begynte å spille vendte guttene på den ene siden av veien seg mot moskeen og brøt ut i en unison stemme, i en særegen høy falsett: «alAsad». Da jeg spurte en av guttene hvorfor de sa «al-Asad», smilte han litt beklemt og svarte at det bare var sånn de gjorde det. De påkalte tydeligvis al-Asads kraft før kampen, uten å tenke noe videre over det. En annen dag satt tre gutter, fra 11 til 15 år, og spilte kort hos familien jeg bodde hos. Den ene ble beskyldt for juks, men nektet. Da tvang de andre ham til å legge ned kortene. «an din alAsad», «forbannet være al-Asad», ropte gutten rasende. Moren hørte besvergelsen, hun fikk sporenstreks tak i guttens far som lot sønnen betale med en ørefik. Faren i huset, fikk jeg senere 
fortalt, hadde selv et spesielt forhold til «al-Asad.» Han var blitt født en måned for tidlig, i 1944, han var familiens førstefødte etter at hans mor hadde mistet flere ufødte barn under tidligere svangerskap. Da hun endelig fødte en levende sønn tok hun ham direkte til al-Asads gravsted for å be om at han fikk vokse opp. Da gutten giftet seg 26 år senere gikk igjen foreldrene med sønnen til gravstedet, klipte en lokk fra håret hans og ofret en geit. Nidr kalte de dette ritualet lokalt, det å gå til Asadis forfar for å be om at hans kraft kunne gjøre slik at de fikk et særskilt ønske oppfylt. Når jeg undersøkte fenomenet nærmere viste det seg at så godt som alle i Deir al-Asad hadde gjennomført et lignende ritual ved al-Asads gravsted, for å be om beskyttelse, om regn, om å bli fertile eller lignende. ${ }^{18}$ Da Israel erobret landsbyen i 1948 skal en israelsk soldat ha omkommet utenfor al-Asadmoskeen i det som kan ha vært en ulykke, men som ifølge enkelte landsbybeboere hadde en annen forklaring. «Folk er så overtroiske her», fortalte den gamle kommunistlederen Hanna Ibrahim fra Deir al-Asads nabolandsby, Bani, «de sa at soldaten døde som et resultat av al-Asads hevn». ${ }^{19}$

Al-Asad var ikke bare integrert i språklig og religiøs lokal idiosynkrasi, men også i lokalpolitikk. Da jeg i oktober 2003 observerte lokalvalget i Deir al-Asad, våknet innbyggerne en morgen til at noen hadde brukt natten på å spre en løpeseddel til så godt som alle husene i den lille byen. Hvis Dhabbah vant valget, stod det i løpeseddelen, ville kisten til al-Asad bli flyttet - til Mahoz, området ovenfor landsbyen med oliventrær, i hovedsak eid av medlemmer av Dhabbahklanen. Dette var det området som ikke hadde blitt berørt av landkonfiskeringene i 1950-1960årene. Løpeseddelen ble knapt tatt alvorlig innad i Dhabbah-leiren, hele ideen var for fjern, og hendelsen forble mer av en kuriositet enn en vellykket provokasjon. Hendelsen kan forstås som et uttrykk for klanpolarisering i lokal arabisk lokalpolitikk. Samtidig er det symptomatisk at forsøket på klanpolarisering i valgkampen, med advarsler om å flytte al-Asad, var helt mislykket. I dag er klanpolarisering på mange områder transendert. Referansen til al-Asad kan like gjerne forstås som territorialitet, som et forsøk på å skape konflikt gjennom å konstruere en trussel mot symbolet på lokal tilhørighet.

\section{«VI FLYKTET MED VÅR AERE»}

«Vi var galne, vi trengte ikke flykte», uttalte en eldre kvinnelig flyktning i Libanon ifølge Benvenisti. ${ }^{20}$ «Ære er kostbar, kvinne», svarer en gammel mann, «skulle vi overlate døtrene våre til jødene?» Historien om araberne, mer opptatt av kvinners ære enn å beskytte sin jord, ble en sentral del av det sionistiske narrativet. «De forlot landet etter nederlaget, selv om det ikke var noe fare for ødeleggelse eller massakrer», uttalte David BenGurion, Israels første statsminister, og la til at ingen jødiske bosetninger ble forlatt i løpet av den arabisk-israelske krigen i $1948 .^{21}$ I denne fortellingen hadde jødene en tilknytning til landet som araberne manglet. Det finnes i dag motforestillinger mot denne versjonen som det er relativt bred faglig enighet om. For det første, at det ikke var grunn til å frykte massakre var en sannhet med modifikasjoner, som Benny Morris ugjenkallelig har vist. Dessuten, for de som flyktet var ikke å ikke kunne returnere en del av vurderingen. Å midlertidig søke dekning ved konflikt var en tilpasning palestinerne hadde utviklet over generasjoner. ${ }^{22}$ De vendte alltid tilbake. Forestillingen om stengte grenser etter at krigshandlinger ga seg var utenkelig. Først høsten 1948 spredte bevisstheten om tvungen eksil seg, ettersom det ble klart at Israel hindret flyktningene i å vende tilbake. Når denne kunnskapen bredte seg sank andelen som flyktet dramatisk. Dette utgjør en viktig del av forklaringen på forskjellen mellom 
nord-områdene og resten av Israel. Mens nær 90 prosent (700 ooo av 800 ooo) ble flyktninger i løpet av 1948-krigen, ble over halvparten av palestinerne igjen i Galilea, som ble erobret i oktober og november i det som var en brutal etnisk renskningskampanje. ${ }^{23}$ Det er påfallende at jo mer brutal den israelske krigføringen mot lokale ble, jo færre flyktet relativt sett.

Forklaringen på dette, hvorfor palestinerne ble igjen snarere enn hvorfor de flyktet, har ikke bare å gjøre med den voksende bevisstheten om at flukt innebar en risiko for ikke å kunne vende tilbake når krigen var over. Det har, som jeg har fremholdt i denne artikkelen, også å gjøre med rurale palestineres idiosynkratiske forhold til sine hjemsteder, snarere enn ære, som en underliggende, praktisk bevissthet, reprodusert over generasjoner. Som i Deir al-Asad har klansolidaritet og småbrukeres lokalisme smeltet sammen med islam i måten innbyggere definerer sin lokale tilhørighet, en tilhørighet territorialitet - som utgjør kjernen i lokal sosial identitet så vel som israelske palestineres etniske identitet.

\section{KONKLUSJON}

Den viktigste form for motstand er ikke den synlige, demonstrasjonene eller de voldelige opprørene - det er ikke manifestering av motstand, men underliggende ideologisk motstand som først og fremst bidrar til å underminere etnokratiske og koloniale prosjekters politiske legitimitet, fordi den bidrar til å skape og forsterke en alternativ etnisk og nasjonal bevissthet. ${ }^{24}$

Dette er vesentlig hvis vi skal forstå hvordan klanens rolle blant israelske palestinere har blitt styrket snarere enn svekket etter opprettelsen av Israel. Under osmanerne var klanen helt sentral for palestinernes måte å organisere lokalsamfunn på, både økonomisk, sosialt og politisk. Senere ble klanen sett på som en barriere mot framveksten av en nasjonal, palestinsk bevissthet av mange sekulære, venstreorienterte palestinske nasjonalister. Men et sentralt aspekt ved klankultur er, som vi har sett i denne artikkelen, territorialitet, deres tilhørighet og beskyttelse av sted. Heller enn å betrakte denne praktiske bevisstheten som en barriere mot israelske palestineres kollektive nasjonale bevissthet, kan den ses som selve kjernen i deres kulturelle tilhørighet til Palestina.

\section{- $f$ •}

DAG TUASTAD er er førstelektor i Midtøstenstudier ved Universitetet i Oslo. Han har blant annet gitt ut boken Palestinske utfordringer (Cappelen Damm Akademisk, 2014).

1 Takk til Babylons redaktører og fagfeller for konstruktive tilbakemeldinger.

2 Blant de mest sentrale er: Benny Morris, The Birth of the Palestinian Refugee Problem, 1947-1949 (New York: Cambridge University Press, 1987); Nafes Nazzal, The Palestinian Exodus from Galilee 1948 (Beirut: The Institute for Palestine Studies, 1978); Ilan Pappe, The Ethnic Cleansing of Palestine (Oxford: Oneworld, 2006).

3 Morris, The Birth, 228, 230.

4 Ranajit Guha, Elementary Aspects of Peasant Insurgency in Colonial India (Delhi: Oxford University Press, 1983), 29, 289-290.

5 Eduardo Archetti, «Rural families and demographic behaviour: some Latin American analogies», Comparative Studies in Society and History 26, nr. 2 (1984): 259.

6 Morris, The Birth, 298.

7 Jeg gjorde også ulike feltarbeid der fra 2002 til 2004 i forbindelse med mitt doktorgradsprosjekt. Jeg er takknemlig overfor Nils Butenschøn som gledelig delte sine kontakter i Deir al-Asad, noe som var av avgjørende betydning for at jeg valgte å gjøre feltarbeid der.

8 Steinbruddet var det samme som er referert til i Muhammad Darwish berømte dikt «Identitetskort», "Jeg er araber, jeg arbeider med mine kamerater i et steinbrudd, ... ingenting er igjen for oss og våre barnebarn unntatt disse steinene, vil regjeringen deres ta dem også, som det blir sagt?» Darwish sin far arbeidet der, og Darwish selv vokste opp i Deir al Asad på 50-tallet som internt fordrevet flyktning.

9 Aharon Layish, «Waqfs and Süfì monasteries in the Ottoman policy of colonization: Sultān Selīm I's waqf of 1516 in favour of Dayr al-Asad», Bulletin of the School of Oriental and African Studies 50, nr.1 (1987): 61.

10 Layish, «Waqfs and Sūfì monasteries», 61-89. 
11 Layish, «Waqfs and Sūfî monasteries», 61, 78.

12 Sabri Jiryis, «The Land Question in Israel». MERIP Reports 47, nr.5, (1976): 18

13 Sabri Jiryis, The Arabs in Israel (New York: Monthly Review Press ,1976), 14.

14 Rabinowitz, D, A. Ghanem'a, og O. Yiftachel: «After the rift: New directions for government policy towards the Arab population in Israel. An Emergency Report by an Interuniversity Research Team submitted to Ehud Barak, Prime Minister of Israel, Jerusalem, 2000»: 59-60. Besøkt 1. september 2018. dirasat-aclp.org/files/after_the_riftenglish.pdf

15 Paul Connerton, How Societies Remember (London: Cambridge University Press, 1989), 80.

16 Nehemia Levtzion, «The dynamics of Sufi brotherhoods», i The Public Sphere in Muslim Societies, red. Miriam Hoexter, Shmuel Noah Eisenstadt, og Nehemia Levtzion (New York: SUNY Press, 2002), 111

17 Danel Bates og Amal Rassam, Peoples and Cultures of the Middle East (New Jersey: Prentice Hall 2001), 73.

18 I 1990 gjorde jeg en kartlegging av 100 hushold i landsbyen 85 av 100 fortalte at de hadde deltatt i denne typer ritual, såkalte nidr-ritual, ved gravstedet til al-Asad.

19 Intervju Bani, juli 2004.

20 Meron Benvenisti, Sacred Landscape: The Buried History of the Holy Land Since 1948 (Berkeley: University of California Press, 2000 [2002]), 247.

21 Benvenisti, Sacred Landscape, 248.

22 Morris, The Birth, 30, 66, 292.

23 Morris, The Birth, 225, 284.

24 Guha, Elementary Aspects; James Scott, Weapons of the Weak (New Haven: Yale University Press, 1985). 